\title{
REPERCUSSÃO DOS TRATADOS INTERNACIONAIS SOBRE DIREITOS HUMANOS NO ORDENAMENTO JURÍDICO BRASILEIRO: APLICAÇÃO DA CONVENÇÃO INTERAMERICANA DE DIREITOS HUMANOS NO CASO "GUERRILHA DO ARAGUAIA"
}

\section{Repercussion of Human Rights Treaties in Brazilian Law: the use of the Inter-American Convention on Human Rights in the "Guerrilha do Araguaia" case ${ }^{1}$}

Priscila Barboza Tavares²

\begin{abstract}
Sumário: 1 Introdução. 2 Guerrilha do Araguaia. 3 Corte Interamericana de Direitos Humanos - Caso Gomes Lund e outros ("Guerrilha do Araguaia") vs. Brasil. 4 Reparações impostas ao Brasil. 5 Efetividade da sentença. 6 Considerações finais.
\end{abstract}

\begin{abstract}
Resumo: O gradativo aumento do reconhecimento dos direitos humanos repercute, na mesma proporção, no Direito Internacional, principalmente no que se refere aos tribunais internacionais no exercício de suas competências. Esse estudo foi realizado com o escopo de investigar a efetividade da sentença proferida pela Corte Internacional de Direitos Humanos no caso Gomes Lund e outros, conhecido como "Guerrilha do Araguaia", no Brasil. Para tanto, realizou-se a descrição do caso para analisar as implicações no direito interno das obrigações, medidas de reparação e indenizações impostas e qual a repercussão prática do cumprimento da sentença pelo Brasil. Nesse estudo sobressaltam-se as dificuldades de cumprimento das obrigações de fazer impostas frente à soberania do país condenado, relevando-se, por outro lado, a crescente importância do julgado no sistema interamericano com a consolidação de um entendimento normativo que produz, progressivamente, um efeito pedagógico dentro do sistema.
\end{abstract}

Palavras-chave: Direito Internacional. Corte Interamericana de Direitos Humanos. Caso Guerrilha do Araguaia. Condenação do Brasil. Efetividade.

Abstract: The increasing recognition of human rights reflected, in the same proportion, in international law, particularly with regard to international courts in the exercise of its competences. This study was conducted with the aim of investigating the effectiveness of the judgment by the International Court of Human Rights, in the case of Gomes Lund and others, known as "Guerrilha do Araguaia", in Brazil. For that, there was the case description to analyze the implications on the domestic law of obligations, remediation and damages imposed and what the practical impact of the completion of the sentence by Brazil. In this study protrude the difficulties of complying with the obligations imposed forward to the sovereignty of the country condemned, pointing up, on the other hand, the increasing importance of the Inter-American system to consolidate a normative understanding that produces increasingly a educational effect within the system.

Key Words: International Law. Inter-American Court of Human Rights. Guerrilla Araguaia.Condenação case of Brazil. Effectiveness.

\section{INTRODUÇÃO}

O progressivo reconhecimento dos direitos humanos em esfera global ocasionou correlatamente algumas transformações, diríamos até evoluções, em importantes dimensões do Direito Internacional. Analisando nuclearmente essa integração da proteção dos direitos humanos e a disseminação dos diplomas

\footnotetext{
${ }^{1}$ DOI deste artigo: http://dx.doi.org/10.12957/cosmopolitan.2014.11925.

${ }^{2}$ Graduanda do Curso de Direito da Universidade Estadual do Maranhão - UEMA.
} 
internacionais nesse sentido, destacamos, dentro do processo de especialização dos tribunais internacionais e das implicações concernentes à jurisdição e competência para a solução de controvérsias internacionais, a sentença de 24 de novembro de $2 \mathrm{2010}^{3}$, proferida pela Corte Interamericana de Direitos Humanos no caso Gomes Lund e outros, conhecido como Guerrilha do Araguaia, na qual o Brasil foi condenado.

A condenação do Brasil no caso Guerrilha do Araguaia traz à baila diversas reflexões quanto às implicações no direito interno das obrigações, medidas de reparação e indenizações que foram impostas pela corte internacional, relevando a discussão acerca da incorporação de convenções internacionais das quais o Brasil é signatário ao direito interno brasileiro, mais especificamente da Convenção Interamericana de Direitos Humanos, quais as implicações das limitações impostas à soberania do Estado brasileiro, e como se dá a implementação da sentença proferida no direito brasileiro.

Para tanto, buscaremos analisar a repercussão dos tribunais internacionais por meio da descrição do caso Guerrilha do Araguaia, destacando o que levou o caso à Corte, a condenação imposta ao Brasil, para sem seguida identificarmos as medidas que o Brasil tem tomado para o cumprimento da sentença, analisando o nível de satisfação e eficácia das mesmas, sem perder de vista as peculiaridades advindas da integração da proteção dos direitos humanos ao Direito Internacional, consoante destaca Emerson Garcia, segundo o qual

os tratados de proteção dos direitos humanos por imporem aos Estados a obrigação de respeito às pessoas submetidas à sua jurisdição, possuem uma natureza especial em relação aos tratados clássicos, que somente geravam obrigações entre os Estados partes 4 .

\section{GUERRILHA DO ARAGUAIA}

Antes de adentrarmos na sentença proferida pela Corte Interamericana no caso Gomes Lund e outros contra o Brasil, comentaremos preliminarmente a respeito da Guerrilha do Araguaia 5 .

3 CorteIDH - Caso Gomes Lund e outros (Guerrilha do Araguaia) c. Brasil. Exceções Preliminares, Mérito, Reparações e Custas. Sentença de 24 de novembro de 2010. Série $\mathrm{C} \mathrm{n}^{0} 219$. Disponível em: <http://www.corteidh.or.cr/docs/casos/articulos/seriec_219_esp.pdf >

4 Emerson Garcia, Proteção Internacional dos Direitos Humanos: breves reflexões sobre os sistemas Convencional e Não-Convencional, $2^{\text {a }}$ ed., Rio de Janeiro: Lumen Juris, 2009, p. 12.

5 A Guerrilha do Araguaia. Disponível em: $<$ http://www.memoriasreveladas.arquivonacional.gov.br/multimidia/araguaia/mapa_o1.swf $>$.

Revista de Direito Internacional do Programa de Pós-Graduação em Direito da UERJ 57 
Repercussão dos tratados internacionais sobre direitos humanos no ordenamento jurídico brasileiro: aplicação da Convenção Interamericana de Direitos Humanos no caso "Guerrilha do Araguaia"

Ocorrida entre 1972 e 1975, a Guerrilha do Araguaia foi um movimento armado desenvolvido pelo Partido Comunista do Brasil, PCdoB, formado por dissidentes do Partido Comunista Brasileiro, na região tríplice fronteira entre os estados do Pará, Maranhão e Goiás (hoje Tocantis), tendo como objetivo central a derrubada do regime militar [...], partindo do campo para a conquista das cidades 6 .

O grupo de guerrilheiros era formado por 69 militantes do PCdoB e por cerca de 20 moradores que aderiram ao movimento, distribuídos em três destacamentos, que buscavam se organizar para alcançar a Revolução Socialista por meio da luta armada. No entanto, os ideais de acabar com o governo repressivo, que censurava a divulgação de notícias e as manifestações artísticas que julgava impróprias, perseguindo àqueles que se opunham ao regime, praticando torturas e inclusive execuções, foram aniquiladas pelas Forças Armadas, que realizou três campanhas militares mobilizando um total de 10 mil homens7.

Relata o historiador Demercino Júnior em relação às incursões militares:

A guerrilha contra os militantes se desenvolveu em três frentes, sendo que nas duas primeiras os comunistas saíram vencedores. Além de não conhecerem a área, os militares não tinham o prestígio da população local. Pelo contrário, eram odiados. Os comunistas se lançavam mata adentro sempre que alguma ameaça era detectada. E sem o apoio da população, o êxito militar era quase impossível. Quase, porque na terceira frente, os militares entraram no jogo. Meses antes do embate, infiltraram tropas entre os ribeirinhos e foram aprendendo sobre a área e colecionando informações sobre os militantes que ali se encontravam. Com algumas doses de crueldade, torturavam locais a fim de descobrirem mais sobre os militantes. E foi com essa "decência" que, em 1973, os comunistas foram cercados e as organizações de esquerda, derrotadas. Os militares se armaram com fuzis FAL (os comunistas possuíam espingardas), abusaram do uso de helicópteros e aviões, atearam fogo em todas as cabanas que encontraram pelo caminho, destruíram depósitos de alimentos que foram construídos nos povoados próximos, e, baseados em informações de delatores e ribeirinhos ludibriados, enfraqueceram os comunistas e os derrotaram. Venceram pelo cansaço ${ }^{8}$.

O combate à Guerrilha do Araguaia foi chamado de "guerra suja", porque não foi um combate divulgado à população brasileira, sendo oficialmente reconhecido apenas vinte anos depois do ocorrido, por meio da revelação de

\footnotetext{
${ }^{6}$ Idem, ibidem.

7 Idem, ibidem.

8 A Guerrilha do Araguaia. Disponível em: <http://guerras.brasilescola.com/seculo-xx/aguerrilhaaraguaia.htm>.

Cosmopolitan Law Journal, v. 2, n. 1, jun. 2014, p. 56-72
} 
extratos de um relatório militar9. O saldo após as operações militares foi de 70 desaparecidos entre militantes e moradores da região ${ }^{10}$, que posteriormente foram considerados desaparecidos políticos, dos quais se tem denúncias de que foram sequestrados, torturados e executados ${ }^{11}$.

Censurada pela ditadura, [a imprensa] não cobria os acontecimentos e muitos nem sabiam o que estava acontecendo no interior do país. Comunistas capturados eram fuzilados ou decapitados. Os militares transformaram as margens do Araguaia em um cemitério aberto ${ }^{12}$.

Algumas informações relevantes sobre os desaparecidos vieram à tona a partir do relatório de Ângelo Arroyo apreendido após a ocorrência da operação nomeada "Massacre da Lapa", em 1976, na qual foram mortos os dirigentes do PCdoB Angelo Arroyo, Pedro Ventura Felipe de Araújo Pomar e João Batista Franco Drummond ${ }^{13}$.

Os familiares dos guerrilheiros do Araguaia iniciaram, em 1982, uma ação judicial para exigir da União esclarecimentos sobre as circunstâncias das mortes de seus parentes e a localização dos corpos. Em 17 de agosto de 1993, a Justiça julgou procedente o recurso impetrado pelos autores para que o mérito da ação fosse julgado, pois não havia nenhuma solicitação de sigilo por parte das Forças Armadas e a lei da anistia não obstruía o direito à verdade contido nas solicitações dos familiares. Até hoje o mérito da ação não foi julgado. Em junho de 1995, considerando esgotados os recursos, os familiares, através da Human Rights Watch e o Centro pela Justiça e o Direito Internacional (CEJIL) enviaram petição à Corte Interamericana de Direitos Humanos da Organização dos Estados Americanos (OEA) [.... ${ }^{14}$.

Trataremos agora da tramitação da petição na Comissão Interamericana de Direitos Humanos, da submissão da demanda à Corte Interamericana de Direitos Humanos e a respectiva sentença proferida, destacando as obrigações, reparações e as medidas de não repetição impostas ao Brasil.

\section{CORTE INTERAMERICANA DE DIREITOS HUMANOS - CASO GOMES LUND E OUTROS ("GUERRILHA DO ARAGUAIA") VS. BRASIL}

\footnotetext{
9 O que foi a Guerrilha do Araguaia? Disponível em: $<$ http://www.pcdob.org.br/duvidas_print.php?id_faq=5>.

${ }^{10}$ A Guerrilha do Araguaia, op.cit., ibidem.

${ }^{11} \mathrm{Os}$ desaparecidos da Guerrilha do Araguaia. Disponível em: $<$ http://www.desaparecidospoliticos.org.br/pagina.php?id=36>

${ }_{12}$ A Guerrilha do Araguaia. Disponível em: <http://guerras.brasilescola...>; op.cit., ibidem.

13 Os desaparecidos da Guerrilha do Araguaia, op.cit., ibidem.

14 Idem, ibidem

Revista de Direito Internacional do Programa de Pós-Graduação em Direito da UERJ 
Repercussão dos tratados internacionais sobre direitos humanos no ordenamento jurídico brasileiro: aplicação da Convenção Interamericana de Direitos Humanos no caso "Guerrilha do Araguaia"

Em 7 de agosto de 1995, o Centro pela Justiça e o Direito Internacional (CEJIL) e a Human Rights Watch/Americas, apresentaram petição à Comissão Interamericana de Direitos Humanos em nome das pessoas desaparecidas durante os conflitos da Guerrilha do Araguaia e de seus familiares. Em 6 de março de 2001 a Comissão expediu o Relatório de Admissibilidade, e em 31 de outubro de 2008 aprovou o Relatório de Mérito n. ${ }^{\circ}$ 91/o8, tudo conforme o que regula a Convenção Americana ${ }^{15}$.

O relatório de mérito foi notificado ao Brasil em 21 de novembro de 2008, concedendo o prazo de dois meses para que exarasse alguma resposta do teor do mesmo. No entanto, as duas prorrogações concedidas para que o Brasil apresentasse informações sobre o cumprimento das transcorreram sem qualquer resposta ou implementação satisfatória ${ }^{16}$.

Diante disso, a Comissão resolveu submeter o caso a jurisdição da Corte Interamericana,

considerando que representava uma oportunidade importante para consolidar a jurisprudência interamericana sobre as leis de anistia com relação aos desaparecimentos forçados e à execução extrajudicial e a consequente obrigação dos Estados de dar a conhecer a verdade à sociedade $\mathrm{e}$ investigar, processar e punir graves violações de direitos humanos. A Comissão também enfatizou o valor histórico do caso e a possibilidade de o Tribunal afirmar a incompatibilidade da Lei de Anistia e das leis sobre o sigilo de documentos com a Convenção Americana ${ }^{17}$.

A demanda referia-se à suposta responsabilidade do Brasil pela detenção arbitrária, tortura e desaparecimento forçado de 70 pessoas, entre militantes e camponeses da região, por conta das operações do exército brasileiro acima comentadas, que objetivaram a erradicação da Guerrilha do Araguaia entre 1972 e 1975. No mais, outro ponto relevante da demanda é a Lei n. ${ }^{\circ} 6.683 / 79$, a Lei de anistia, em virtude da qual o Brasil não realizou qualquer investigação que visasse o julgamento e a punição das pessoas responsáveis, além de não ter sido assegurado aos familiares dos desaparecidos acesso à informação sobre a Guerrilha do Araguaia, nem por recursos judiciais de natureza civil, tendo em vista que o Brasil adotou medidas legislativas e administrativas que restringiram

15 CorteIDH - Caso Gomes Lund e outros (Guerrilha do Araguaia) c. Brasil. Exceções Preliminares, Mérito, Reparações e Custas. Sentença de 24 de novembro de 2010. Série $\mathrm{C} \mathrm{n}^{0} 219$. p. 3 .

${ }_{16}$ Idem, ibidem.

17 Idem, ibidem. 
indevidamente o direito de acesso à informação ${ }^{18}$.

A Comissão solicitou ao Tribunal que declare que o Estado é responsável pela
violação dos direitos estabelecidos nos artigos 3 (direito ao reconhecimento
da personalidade jurídica), 4 (direito à vida), 5 (direito à integridade pessoal),
7 (direito à liberdade pessoal), 8 (garantias judiciais), 13 (liberdade de
pensamento e expressão) e 25 (proteção judicial), da Convenção Americana
sobre Direitos Humanos, em conexão com as obrigações previstas nos artigos
1.1 (obrigação geral de respeito e garantia dos direitos humanos) e 2 (dever de
adotar disposições de direito interno) da mesma Convenção. Finalmente,
solicitou à Corte que ordene ao Estado a adoção de determinadas medidas de
reparaçãón

Com relação aos direitos violados, frisaremos o posicionamento da Corte em relação a alguns deles, antes de adentrarmos nas medidas de reparação impostas. Um primeiro ponto importante diz respeito a um dos fundamentos jurídicos tomados pela Corte que sustenta o desaparecimento forçado de pessoas como uma violação permanente aos bens jurídicos tutelados pela Convenção, configurado por uma pluralidade de condutas voltadas para um mesmo fim, que são simultâneas e constitutivas do desaparecimento forçado, tais como a privação de liberdade, intervenção direta dos agentes estatais ou sua aquiescência, negativas de fornecer informações referentes aos desaparecidos, dentre outras. Ocorre que, consoante o entendimento da Corte ${ }^{20}$, enquanto for desconhecido o paradeiro da pessoa, tem-se como permanente o ato de desaparecimento e execução. Assim,

Em conformidade com todo o exposto, a Corte reiterou que o desaparecimento forçado constitui uma violação múltipla de vários direitos protegidos pela Convenção Americana, que coloca a vítima em um estado de completa desproteção e acarreta outras violações conexas, sendo especialmente grave quando faz parte de um padrão sistemático ou prática aplicada ou tolerada pelo Estado ${ }^{21}$.

A Corte destaca a grave violação aos princípios essenciais que fundamentam o Sistema Interamericano de Direito Humanos, de modo que a proibição dos desaparecimentos forçados, alçados em grave violação aos direitos humanos alcançou o caráter de jus cogens, o que fortalece o dever do Estado de salvaguardar os direitos humanos por meio de medidas jurídicas, políticas e administrativas ${ }^{22}$. Assim, o entendimento da Corte é que quando há motivos razoáveis para a suspeita do desaparecimento forçado de uma pessoa,

\footnotetext{
${ }^{18}$ CorteIDH. Op. cit. p. 4.

19 Idem, ibidem.

${ }^{20}$ CorteIDH. Op. cit. p. 38.

${ }^{21}$ Idem, ibidem.

${ }^{22}$ CorteIDH. Op. cit. p.39-40.
}

Revista de Direito Internacional do Programa de Pós-Graduação em Direito da UERJ 
Repercussão dos tratados internacionais sobre direitos humanos no ordenamento jurídico brasileiro: aplicação da Convenção Interamericana de Direitos Humanos no caso "Guerrilha do Araguaia"

independentemente de representação, "[...] o Direito Internacional e o dever geral de garantia impõem a obrigação de investigar o caso ex officio, sem dilação, e de maneira séria, imparcial e efetiva" ${ }^{23}$.

Por conta disso, a Corte recomenda para a efetividade das investigações e prevenção de futuras violações de mesma natureza, que os Estados estabeleçam um marco normativo, regulamentando o desaparecimento forçado de pessoas como delito autônomo em suas legislações internas"24. "Outrossim, o Estado deve garantir que nenhum obstáculo normativo ou de outra índole impeça a investigação desses atos, e se for o caso, a punição dos responsáveis" ${ }^{25}$, consoante o acordado na Convenção Americana. Retomaremos mais a frente essa questão.

No caso Guerrilha do Araguaia em específico, embora o Brasil não tenha reconhecido expressamente sua responsabilidade internacional pelo ocorrido, internamente o fez, adotando diversas maneiras de reparação, por meio da Lei n. ${ }^{\circ}$ 9.140/95, que, dentre outras providências, criou a Comissão Especial sobre Mortos e Desaparecidos Políticos, para viabilizar o reconhecimento das vítimas e as respectivas indenizações ${ }^{26}$. Deste modo, a responsabilidade estatal pelo desaparecimento forçado é um ponto incontroverso, havendo, no entanto, discordância entre as partes no que tange às obrigações internacionais do Brasil em consonância com a Convenção Americana sobre Direitos Humanos.

Desse modo, a Corte Interamericana deve decidir, no presente caso, se a Lei de Anistia sancionada em 1979 é ou não compatível com os direitos consagrados nos artigos 1.1, 2, 8.1 e 25 da Convenção Americana ou, dito de outra maneira, se aquela pode manter seus efeitos jurídicos a respeito de graves violações de direitos humanos, uma vez que o Estado obrigou-se internacionalmente a partir da ratificação da Convenção Americana ${ }^{27}$.

Durante a fase do relatório da Comissão, o Brasil informara que a investigação e a punição dos responsáveis pelos desaparecimentos forçados foram impossibilitados pela Lei de Anistia, a Lei 6.683/79, cuja interpretação dada pelo Estado brasileiro impediu também que os familiares das vítimas e a sociedade brasileira pudessem ter acesso às informações referentes ao ocorrido ${ }^{28}$. No entanto, contrário é o entendimento da Corte:

${ }^{23}$ CorteIDH. Op. cit. p.40.

24 CorteIDH. Op. cit. p.41.

25 Idem, ibidem.

${ }^{26}$ CorteIDH. Op. cit. p.42-43.

${ }_{27}$ CorteIDH. Op. cit. p.47.

${ }^{28}$ Idem, ibidem.

62

Cosmopolitan Law Journal, v. 2, n. 1, jun. 2014, p. 56-72 
A aplicação de leis de anistia a perpetradores de graves violações de direitos humanos é contrária às obrigações estabelecidas na Convenção e à jurisprudência da Corte Interamericana. Em casos de execução e desaparecimento forçado, os artigos 8 e 25 da Convenção estabelecem que os familiares das vítimas têm o direito a que essa morte ou desaparecimento seja efetivamente investigado pelas autoridades estatais, que os responsáveis sejam processados e, se for o caso, punidos, e que se reparem os danos que os familiares tenham sofrido. Do mesmo modo, nenhuma lei ou norma de direito interno, como as disposições de anistia, as regras de prescrição e outras excludentes de responsabilidade, pode impedir que um Estado cumpra essa obrigação, especialmente quando se trate de graves violações de direitos humanos que constituam crimes contra a humanidade, como os desaparecimentos forçados do presente caso, pois esses crimes são inanistiáveis e imprescritíveis ${ }^{29}$.

Aqui nos deteremos em algumas questões levantadas pelo Brasil como obstaculizadoras do cumprimento da obrigação de investigar e sancionar as violações de direitos humanos no caso em comento. A primeira delas consiste no maior obstáculo legal, a Lei de Anistia, que assim dispõe no caput do art. $1^{\mathrm{o}}$ :

Art. $1^{\mathrm{o}}$ É concedida anistia a todos quantos, no período compreendido entre 02 de setembro de 1961 e 15 de agosto de 1979, cometeram crimes políticos ou conexos com estes, crimes eleitorais, aos que tiveram seus direitos políticos suspensos e aos servidores da Administração Direta e Indireta, de fundações vinculadas ao poder público, aos Servidores dos Poderes Legislativo e Judiciário, aos Militares e aos dirigentes e representantes sindicais, punidos com fundamento em Atos Institucionais e Complementares ${ }^{3}$. (GRIFO NOSSO)

O cerne do obstáculo legal proveniente desta lei é a interpretação conferida no âmbito interno que considera crimes conexos aos crimes políticos todos os crimes cometidos pelos agentes do Estado, inclusive todas as graves violações aos direitos humanos praticadas. Esse entrave legal é o maior obstáculo à garantia do acesso à justiça e à verdade pelos familiares dos desaparecidos ${ }^{31}$, interpretação esta que foi referendada pelo Supremo Tribunal Federal na ADPF 153, na qual a Suprema Corte rejeitou o pedido da Ordem dos Advogados do Brasil (OAB) por uma revisão da Lei de Anistia ${ }^{32}$, ressaltando o contexto histórico e político que levou à edição da Lei, e ainda que "não cabe ao Poder Judiciário rever o acordo político que, na transição do regime militar para a democracia, resultou na anistia

\footnotetext{
29 CorteIDH. Op. cit. p.47-48.

$3^{30}$ Lei n. ${ }^{\circ} 6.683$ de 24 de agosto 1979 - Concede anistia e dá outras providências.

${ }^{31}$ CorteIDH. Op. cit. p.48.

${ }^{32} \mathrm{STF}$ é contra revisão da Lei da Anistia por sete votos a dois. Disponível em: <http://www.stf.jus.br/portal/cms/verNoticiaDetalhe.asp?idConteudo=125515>

Revista de Direito Internacional do Programa de Pós-Graduação em Direito da UERJ 63
} 
Repercussão dos tratados internacionais sobre direitos humanos no ordenamento jurídico brasileiro: aplicação da Convenção Interamericana de Direitos Humanos no caso "Guerrilha do Araguaia"

de todos aqueles que cometeram crimes políticos e conexos a eles no Brasil entre 2 de setembro de 1961 e 15 de agosto de 1979"33.

Assim, o Brasil embasou a aprovação da Lei de Anistia como uma etapa do processo de transição política e redemocratização que o país enfrentou pós ditadura, de modo que a punição dos crimes contra os direitos humanos passou a representar, como usualmente ocorre nos casos similares, um obstáculo à transição e ao alcance da "reconciliação nacional"34. Ademais, o Brasil "destacou que a Lei de Anistia foi antecedida de um debate político e foi considerada, por muitos, um passo importante para a reconciliação nacional” 35 .

Com referência a isso, principalmente "ao falso dilema entre paz ou reconciliação, por um lado, e justiça, por outro"36, que a Corte destaca os reiterados pronunciamentos 37 no Sistema Interamericano de Direitos Humanos, assim como nos demais órgãos internacionais de proteção aos direitos humanos de âmbito universal e regional, sobre a incompatibilidade das leis de anistia com as obrigações convencionais dos Estados, quando se trata de graves violações dos direitos humanos, enfatizando que

as anistias e outras medidas análogas contribuem para a impunidade e constituem um obstáculo para o direito à verdade, ao opor-se a uma investigação aprofundada dos fatos, e são, portanto, incompatíveis com as obrigações que cabem aos Estados, em virtude de diversas fontes de Direito Internacional. ${ }^{8}$

O segundo obstáculo indicado é a prescrição, e o terceiro a falta de tipificação do crime de desaparecimento forçado no direito brasileiro, o que tornaria uma posterior tipificação uma afronta aos princípios da legalidade e da irretroatividade da lei penal, considerando que no Brasil as únicas hipóteses constitucionais de imprescritibilidade são a prática do racismo e a ação de grupos armados contra a ordem constitucional, além da previsão do princípio da legalidade e da irretroatividade na Convenção Americana 39.

Ainda sobre a Lei de Anistia, cumpre ressaltar o entendimento da Corte de que é dever do Estado, após ratificar a Convenção Americana, acabar com os

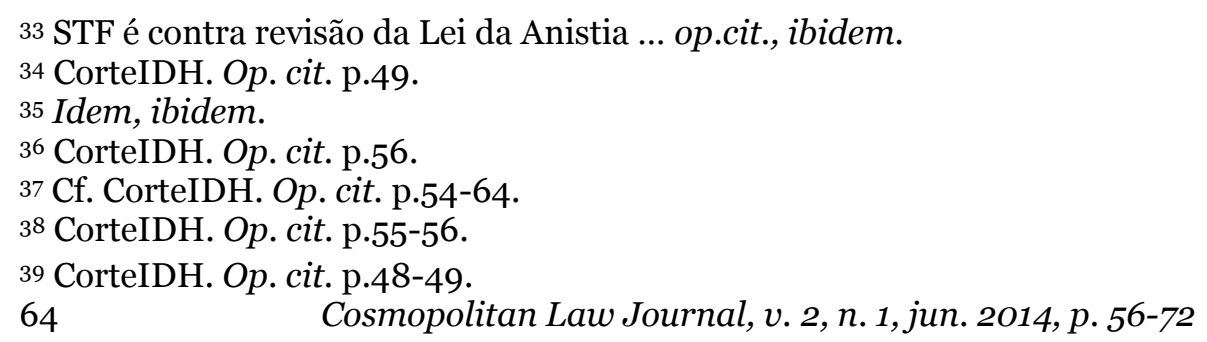


efeitos das disposições legais que a contrariem, e por conta disso, a Lei de Anistia, incompatível com a Convenção, careceria de efeitos jurídicos. Ademais, a respeito da incompatibilidade, esta não é decorrente de uma questão formal, referente ao processo de criação da lei, e sim a ratio legis, qual seja, "deixar impunes graves violações ao direito internacional cometidas pelo regime militar" 40.

Diante desse panorama, a Corte determinou ao Brasil que cumprisse, diante da obrigação do Estado de adequar seu direito interno ao quanto disposto na Convenção Americana, algumas medidas de reparação. Adiante comentaremos as medidas mais pertinentes e relevantes para a discussão proposta.

\section{REPARAÇÕES IMPOSTAS AO BRASIL}

Destacamos entre as reparações impostas a obrigação do Brasil de investigar os fatos, julgar, e se for o caso, punir os responsáveis, consoante as sanções e consequências que a lei preveja, não podendo utilizar “[...] disposições de direito interno, como prescrição, coisa julgada, irretroatividade da lei penal e ne bis in idem, nem qualquer excludente de responsabilidade similar, para eximir-se de seu dever" ${ }^{41}$, procedendo com as medidas necessárias para que a Lei de anistia e as leis de sigilo não continuem a ser obstáculos à persecução penal.

O Estado ainda deve realizar todos os esforços para determinar o paradeiro das vítimas desaparecidas, para que sejam identificados e entregues os restos mortais aos familiares. Cabe ainda ao Brasil oferecer tratamento médico e psicológico ou psiquiátrico às vítimas que o requeiram, como uma medida de reparação aos sofrimentos físicos e psicológicos sofridos pelos familiares, que também se tornaram vítimas 42 .

Outras medidas de satisfação referem-se à publicação da sentença proferida pela Corte no Diário Oficial, em um diário de circulação nacional, e em um sítio eletrônico do Estado, e à realização de um ato público de reconhecimento de responsabilidade internacional a respeito do caso 43.

${ }^{40}$ CorteIDH. Op. cit. p.65.

${ }^{41}$ CorteIDH. Op. cit. p.95.

${ }^{42}$ CorteIDH. Op. cit. p. 99.

43 CorteIDH. Op. cit. p.100-101.

Revista de Direito Internacional do Programa de Pós-Graduação em Direito da UERJ 
Repercussão dos tratados internacionais sobre direitos humanos no ordenamento jurídico brasileiro: aplicação da Convenção Interamericana de Direitos Humanos no caso "Guerrilha do Araguaia"

Como garantias de não repetição a Corte determinou que o Brasil implementasse, em prazo razoável, um programa ou curso permanente e obrigatório sobre direitos humanos a todos os níveis hierárquicos das forças armadas. A outra medida de não repetição de grande repercussão no direito interno foi a imposição de que o país tome as medidas necessárias para tipificar o delito de desaparecimento forçado de pessoas em conformidade com os parâmetros interamericanos. No mais

Essa obrigação vincula a todos os poderes e órgãos estatais em seu conjunto. Nesse sentido, como esta Corte salientou anteriormente, o Estado não deve limitar-se a promover o projeto de lei de que se trata, mas assegurar sua pronta sanção e entrada em vigor, de acordo com os procedimentos estabelecidos no ordenamento jurídico interno. Enquanto cumpre essa medida, o Estado deverá adotar todas aquelas ações que garantam o efetivo julgamento e, se for o caso, punição dos fatos constitutivos do desaparecimento forçado, através dos mecanismos existentes no direito interno 44 .

No mais, ordenou que o Brasil continue a conduzir iniciativas de busca, sistematização e publicação das informações sobre a Guerrilha do Araguaia, e sobre as demais violações de direitos humanos perpetradas durante o regime militar, garantindo acesso às mesmas 45 , exortando a iniciativa do país criar a Comissão da Verdade, julgando ser este um importante mecanismo para garantir o direito de conhecer a verdade, que "[...] pode contribuir para a construção e preservação da memória histórica, o esclarecimento de fatos e a determinação de responsabilidades institucionais, sociais e políticas em determinados períodos históricos de uma sociedade 46".

Por fim, determinou quantias que o Estado terá que pagar a título de dano material, imaterial e restituição de custas e gastos aos familiares das vítimas. Passaremos agora, à luz do Direito Internacional Público e das normas de direito interno, a analisar a efetividade dessas determinações no direito brasileiro.

\section{EFETIVIDADE DA SENTENÇA}

Primordialmente, cumpre afirmar a competência da Corte Interamericana de Direitos Humanos para conhecer o caso, proveniente da condição do Brasil de parte da Convenção Americana, desde 1992, e deste ter reconhecido a

\footnotetext{
44 CorteIDH. Op. cit. p.104-105.

45 CorteIDH. Op. cit. p.106.

${ }^{46}$ CorteIDH. Op. cit. p.107.

66

Cosmopolitan Law Journal, v. 2, n. 1, jun. 2014, p. 56-72
} 
competência contenciosa da Corte desde 1998 47. A esse respeito só podem ser submetidos à decisão da Corte os Estados-partes da Convenção que declararem reconhecerem de pleno direito e sem convenção especial a competência da Corte nos casos relativos à interpretação ou aplicação da Convenção.

Quanto a isso, na esteira do que discute Wagner Menezes (2013) 48, é evidente que todo Tribunal Internacional, a exemplo da Corte Interamericana, possui jurisdição internacional, porém, diante do fenômeno de jurisdicionalização do Direito Internacional, hoje é plenamente possível ao Estado ter acesso a vários tribunais para a discussão dos litígios, o que releva a importância da competência como delimitação da jurisdição, definindo "[...] o âmbito de exercício da atividade jurisdicional de cada Tribunal Internacional e os limites da matéria em que ele está encarregado", estabelecida mediante Tratado 49.

Superado o ponto quanto à competência da Corte para determinar medidas ao Brasil, surgem oposições no que tange a obrigação do Brasil de cumprir tais medidas, considerando a soberania do Estado, da onde se aduz uma subordinação do país à organização internacional e ao Tribunal, convolando uma afronta à soberania. Nesse ponto, merece menção a reflexão de Emerson Garcia ${ }^{50}$, para quem o estreitamento das relações internacionais e o reconhecimento da necessidade de proteção dos direitos humanos relativizou vários aspectos da soberania nacional, antes tida como absoluta.

Assim, alguns aspectos permanecem, a exemplo da igualdade soberana entre os Estados, a plena capacidade jurídica e independência dos estados entre si e perante os demais sujeitos de Direito Internacional. No entanto, a coexistência da soberania com outros princípios tão importantes quanto para o Direito Internacional, tal como a proteção dos direitos humanos, acabou por limitar a própria soberania, sem no entanto suprimi-la. No que tange à Guerrilha do Araguaia, por se tratar de grave violação aos direitos humanos, violação esta perpetrada pelo próprio Estado soberano aos seus cidadãos, ainda maior tornase essa delimitação da soberania.

47 CorteIDH. Op. cit. p.2O.

${ }^{48}$ Wagner Menezes, Tribunais internacionais: Jurisdição e Competência. São Paulo: Saraiva, 2013. p. 331-334.

49 Idem, p. 334.

${ }^{50}$ Emerson Garcia, op.cit. p. 10-11.

Revista de Direito Internacional do Programa de Pós-Graduação em Direito da UERJ 
Em se tratando de proteção dos direitos humanos, o Direito Internacional não mais desempenha o papel de coordenador de individualidades iguais, absolutas e intangíveis, como eram concebidos os Estados, o que necessariamente impõe o redimensionamento do clássico conceito de soberania. ${ }^{1}$

Desta feita, embora soberano, o Brasil é limitado pelas obrigações concernentes à garantia dos direitos humanos fundamentais e reparação das violações praticadas pelas quais voluntariamente se obrigou, no exercício de sua soberania, tendo previamente anuído às regras e preceitos da Convenção Americana. Destarte, "atributo fundamental do Estado, a soberania o faz titular de competências que, precisamente porque existe uma ordem jurídica internacional, não são ilimitadas"52.

O maior entrave, no entanto, à efetividade da sentença é a disponibilidade de mecanismos que a torne efetiva no âmbito interno. No que tange ao cumprimento da determinação de investigar os fatos, julgar, e se for o caso, punir os responsáveis, constata-se uma antinomia entre o direito internacional e o direito interno brasileiro.

O conflito de normas ocorre quando estas regulam de maneiras díspares as mesmas situações 53. No caso em apreço, a Lei de Anistia, norma do direito interno brasileiro, está em conflito com a Convenção Americana de Direitos Humanos. Assim, questiona-se qual das duas devem ser aplicadas, mesmo considerando a suposta obrigação do Brasil de adequar as normas internas ao constante na Convenção. O que se vê na prática, no entanto, é o inverso. Em vez da adequação dos países ao que ratificam nos tratados, a maior parte dos Estados regulam o modo como as normas de Direito Internacional se compatibilizam ao direito interno.

As antinomias são resolvidas primeiramente por um critério hierárquico, de modo que a norma hierarquicamente superior derroga a norma hierarquicamente inferior. Porém, quando as normas em conflito são de mesma hierarquia, aplicam-se os critérios cronológico e da especialidade54. No Brasil não

\footnotetext{
${ }^{11}$ Idem, p. 15 .

${ }^{2}$ Francisco Rezek, Direito Internacional Público - Curso Elementar.14 a ed. São Paulo: Saraiva, 2013. p. 265.

53 Paulo Portela, Direito Internacional Público e Privado. $2^{\mathrm{a}}$ ed, Salvador: Juspodvm, 2010. p.125. 54 Idem, p.125. 
há uma hierarquia uniforme aos tratados, de modo que sua posição no ordenamento jurídico varia consoante a matéria que tratam.

Inicialmente, destacamos que a jurisprudência brasileira nunca acolheu a noção de supraconstitucionalidade dos tratados definida nos arts. 29 e 46 da Convenção de Viena. Quanto aos tratados de modo geral firmou-se o entendimento de que possuem status de norma infraconstitucional, equiparados às leis ordinárias.

Posicionamento diverso ocorre com os tratados de direitos humanos, como é o caso da Convenção Americana. Pós Emenda Constitucional no 45 , que introduziu o $\S 3^{\circ}$ ao art. $5^{\circ}$ da Constituição Federal, foi dado tratamento de maior importância aos tratados que versem sobre essas matérias. Nessa esteira, o entendimento majoritário do STF quanto à hierarquia desses tratados é o de supralegalidade, consoante julgamento do HC 90.172/SP 55. Há também, de posição minoritária, o entendimento de que os tratados de direitos humanos seriam materialmente constitucionais 56 .

No que tange a supralegalidade,

As normas supralegais são aquelas que continuam hierarquicamente inferiores à Constituição Federal, mas que estão acima das demais espécies normativas nacionais. No campo específico dos direitos humanos, a supralegalidade parte da premissa de que os tratados de direitos humanos trazem normas que estão diretamente vinculadas à proteção da dignidade humana e que, por isso, têm importância superior no ordenamento jurídico, não podendo ser derrogadas por outras leis ordinárias simplesmente por serem estas mais novas ou especiais57.

Observa-se, pois, adotada a noção de supralegalidade dos tratados de direitos humanos no ordenamento jurídico brasileiro, que na antinomia entre a Lei de Anistia e a Convenção Americana, esta seria hierarquicamente superior a Lei de Anistia, derrogando-a, o que findaria com as barreiras à investigação dos fatos e eventual punição dos responsáveis.

Quanto à tipificação do delito de desaparecimento forçado cabem outras observações. Essa determinação requer um esforço legislativo, o que gera maiores óbices ao cumprimento estatal. Nesse aspecto, a Corte instou o Brasil a seguir

55 SUPREMO TRIBUNAL FEDERAL, Segunda Turma, HC 90.172/SP. Relator: Gilmar Mendes, Brasília, DF, 05. jun. 07, DJ 17.08.07, p. 91.

${ }^{6}$ Paulo Portela... op. cit. p.744.

57 Idem, p. 743-744.

Revista de Direito Internacional do Programa de Pós-Graduação em Direito da UERJ 
Repercussão dos tratados internacionais sobre direitos humanos no ordenamento jurídico brasileiro: aplicação da Convenção Interamericana de Direitos Humanos no caso "Guerrilha do Araguaia"

com a tramitação dos Projetos de Lei no 301 , de 2007 e n ${ }^{0} 4.038$, de 2008, porém complementando-os com a tipificação em sentido interamericano.

Ainda com referência à iniciativa legislativa, importa mencionar a edição da Lei n. ${ }^{0}$ 12.530/2012, que criou a Comissão Nacional da Verdade, destinada a examinar e esclarecer as graves violações de direitos humanos praticadas de 1946 a 1988, com a finalidade de "[...] efetivar o direito à memória e à verdade histórica e promover a reconciliação nacional” 58 .

As indenizações, por seu turno, devido seu caráter pecuniário, consoante o $\S 1^{\circ}$ do art. 68 da Convenção Americana, possuem eficácia executiva, de forma que o eventual inadimplemento do Brasil enseja a propositura de ação judicial executiva. Por fim, ressaltamos que a sentença é definitiva e inapelável 59, e o seu cumprimento deve ser espontâneo, imediato e integral, consoante o art. 68 da Convenção, o que na prática, no entanto, demanda muito mais tempo e vontade política do que o desejável.

\section{CONSIDERAÇÕES FINAIS}

A multiplicação de tratados internacionais que versam sobre direitos humanos trouxe diversas alterações nas relações internacionais e nas concepções do Direito Internacional Clássico. Umas das discussões em voga giram em torno dos sujeitos de direito internacional público. Diante das peculiaridades dos tratados que versam sobre essa matéria, por gerar de um lado obrigações dos Estados frente às pessoas submetidas à sua jurisdição, por outro lado, também se ampliou o entendimento acerca da personalidade internacional, em decorrência da possibilidade dos indivíduos, grupos de indivíduos e organizações não governamentais poderem denunciar a violação dos direitos previstos na Convenção à Comissão, como ocorreu no caso Guerrilha do Araguaia.

Ora, essa possibilidade inegavelmente amplia os sujeitos ativos na sociedade internacional, além de aumentar o acesso à jurisdição internacional, o que leva parte da doutrina a admitir a existência de novos sujeitos de Direito Internacional, além dos Estados e das organizações internacionais. Incontroverso, apenas a constante evolução do direito internacional, principalmente no que tange aos direitos humanos.

${ }^{8}$ Art. $1^{\mathrm{o}}$, caput, da Lei n. ${ }^{\mathrm{o}}$ Lei n. ${ }^{\mathrm{o}}{ }^{12.530 / 2012 .}$

59 Wagner Menezes... op. cit. p. 191.

Cosmopolitan Law Journal, v. 2, n. 1, jun. 2014, p. 56-72 
Nesse diapasão, destacamos a importância do caso Guerrilha do Araguaia no sistema interamericano. No Brasil a sentença repercutiu sobressaltando a importância da consolidação de instrumentos e mecanismos aptos a efetivar a sentenças internacionais, de toda a questão da hierarquia dos tratados no ordenamento jurídico interno e da necessidade de adequação do direito interno brasileiro às normas de direito internacional com as quais o Brasil voluntariamente pactua, se responsabilizando internacionalmente pelos descumprimentos que incorre, e que não raro reincide.

O Brasil se vê responsável internacionalmente a rever a Lei de Anistia, a tipificar o delito de desaparecimento forçado, a investigar o ocorrido na Guerrilha da Araguaia, identificar os responsáveis, e puni-los. Deve ainda indenizar os familiares das vítimas por anos de descaso e segredo, e prestar os devidos esclarecimentos como garantia do direito à verdade e à memória histórica aos familiares e a todos os brasileiros, para que nunca sejam esquecidas as graves violações perpetradas, e como garantia de que tais práticas não sejam repetidas.

Se o Brasil cumprirá integralmente ou parcialmente a sentença, isso não temos como saber. Mas de um modo ou de outro, a importância do caso no sistema interamericano já surte efeitos como um delineamento de um entendimento jurisprudencial da Corte Interamericana de Direitos Humanos, que na oportunidade buscou a consolidação de um entendimento normativo a fim de que este sirva de diretriz tanto para outras decisões como para a interpretação das normas do Direito Internacional nesse mesmo sentido. Deste modo, progressivamente, as sentenças produzem um efeito pedagógico, à medida que orientam e incutem nos Estados o dever de observar os Direitos Humanos na organização política, no ordenamento jurídico, e em todas as suas ações.

É preciso ultrapassar o positivismo exacerbado, pois só assim se entrará em um novo período de respeito aos direitos da pessoa, contribuindo para acabar com o círculo de impunidade no Brasil. É preciso mostrar que a Justiça age de forma igualitária na punição de quem quer que pratique graves crimes contra a humanidade, de modo que a imperatividade do Direito e da Justiça sirvam sempre para mostrar que práticas tão cruéis e desumanas jamais podem se repetir, jamais serão esquecidas e a qualquer tempo serão punidas. ${ }^{60}$

\section{REFERÊNCIAS}

ARQUIVO NACIONAL - Centro de Referência das Lutas Políticas no Brasil. Guerrilha do Araguaia. Disponível em:

${ }^{60}$ CorteIDH. Op. cit. p.126.

Revista de Direito Internacional do Programa de Pós-Graduação em Direito da UERJ $\quad 71$ 
$<$ http://www.memoriasreveladas.arquivonacional.gov.br/multimidia/araguaia/ mapa_01.swf $>$.

CENTRO DE DOCUMENTAÇÃO EREMIAS DOLIZOICOV. Os desaparecidos da Guerrilha do Araguaia. Disponível em: $<$ http://www.desaparecidospoliticos.org.br/pagina.php?id=36>.

CIDH. Caso Gomes Lund e outros (Guerrilha do Araguaia) c. Brasil. Exceções Preliminares, Mérito, Reparações e Custas. Sentença de 24 de novembro de 2010. Série $\mathrm{C}^{0} 219$.

GARCIA, Emerson. Proteção Internacional dos Direitos Humanos: breves reflexões sobre os sistemas Convencional e Não-Convencional, $2^{\mathrm{a}}$ ed., Rio de Janeiro: Lumen Juris, 2009.

JUNIOR, Demercino. A Guerrilha do Araguaia. Disponível em: $<\mathrm{http}$ //guerras.brasilescola.com/seculo-xx/a-guerrilha-araguaia.htm>.

MENEZES, Wagner. Tribunais internacionais: Jurisdição e Competência. São Paulo: Saraiva, 2013.

PARTIDO COMUNISTA DO BRASIL. O que foi a Guerrilha do Araguaia? Disponível em: <http://www.pcdob.org.br/duvidas_print.php?id_faq=5>.

PORTELA, Paulo. Direito Internacional Público e Privado, $2^{\text {a }}$ ed. Salvador: Juspodivm, 2010.

REZEK, Francisco. Direito Internacional Público - Curso Elementar, $14^{\mathrm{a}}$ ed. São Paulo: Saraiva, 2013.

SUPREMO TRIBUNAL FEDERAL. STF é contra revisão da Lei da Anistia por sete votos a dois. Notícia do serviço de imprensa do STF em 29/04/2010, disponível em: $<$ http://www.stf.jus.br/portal/cms/verNoticiaDetalhe.asp?idConteudo=125515 $>$ 